\title{
ENTRE SOFIE Y TOVELILLE. \\ LAS ESCUELAS DE LA COMUNIDAD DANESA FRENTE AL PROBLEMA DE LA IDENTIDAD NACIONAL DE LAS GENERACIONES NACIDAS EN LA ARGENTINA (1886-1930)
}

POR

MARÍA M. BJERG

Instituto de Estudios Histórico-Sociales, Universidad del Centro, Tandil, Argentina

\begin{abstract}
Este trabajo examina algunos aspectos del proceso de adaptación a la nueva sociedad de un grupo étnico noreuropeo: los daneses asentados en el mundo rural de los partidos del centro-sur de la provincia de Buenos Aires (Argentina). El análisis intenta comprender cuál fue la influencia que, entre los daneses de la Argentina, tuvo un movimiento de base religiosa, de gran difusión en Dinamarca durante las tres últimas décadas del siglo XIX, que intentaba reavivar el sentimiento nacional danés tras la derrota en la guerra contra Prusia en 1864. El trabajo centrará su atención en el rol de la iglesia evangélica luterana danesa de la Argentina en la retención de la identificación religiosa y nacional de este grupo inmigratorio; $y$ en las funciones atribuidas por la propia iglesia, a las escuelas de la comunidad en la creación de una doble identidad nacional, a través de la difusión y de la preservación de los valores socio-culturales y de la iconografía nacional danesa entre las generaciones nacidas en la Argentina.
\end{abstract}

\section{LOS INMIGRANTES Y EL PASADO DANÉS}

Los primeros daneses llegaron a la Argentina en la década de 1860 alentados por un pionero que había vivido en el partido de Tandil desde 1848 y que en una visita a su patria, realiza- 
da en 1859, convenció a un pequeño núcleo de compatriotas para probar suerte en la Argentina y acompañarlo en su viaje de regreso. El grupo era originario de la isla de Mön. Una vez asentada esta primera célula se inició un proceso migratorio que atrajo hacia Tandil a unas cuantas centenas de daneses provinientes del distrito de Maribo formado por Mön, LollandFalster y otras islas menores del sudeste de Dinamarca.

Durante la década de 1870 y la primera mitad de los años 1880 la corriente migratoria danesa hacia la Argentina se mantuvo en niveles inferiores a los cincuenta ingresos anuales, cobró brios en los años previos a la crisis de Baring, superando los 300 inmigrantes por año, volvió a decaer hasta los albores del nuevo siglo y alcanzó sus registros más altos entre 1910 y la Primera Guerra con más de mil entradas anuales (1).

Hacia 1890, las redes que atraían inmigrantes desde la región sudeste de Dinamarca sin desaparecer completamente dieron paso a una participación más equitativa del resto del país en la corriente migratoria que se dirigía hacia la Argentina, con una mayoría de trabajadores rurales del centro y norte de la península de Jutlandia y de obreros no calificados de las industrias de Copenhague.

Una vez en la Argentina, Tandil dejó de ser el único destino posible. Entre la crisis de 1890 y el viernes negro de Wall Street el mundo rural de Tres Arroyos, Necochea y Coronel Dorrego se transformó en el sitio preferido por estos rubios luteranos del norte de Europa. Provenientes de un país cuya principal actividad económica era la agricultura y donde acceder a una parcela de tierra se había transformado para muchos en el reaseguro de la sobrevivencia, el objetivo de la mayor parte de los daneses que arribaban a la Argentina no era la ciudad sino el campo. Hasta fines de la década de 1880, el distrito de Tandil satisfacía estas expectativas. Pero cuando las posibilidades de incorporarse a la actividad productiva rural se vieron obstaculizadas porque la tierra disponible había sido ocupada prácticamente en su totalidad, los daneses iniciaron una marcha lenta aunque firme hacia los otros partidos del centro-sur bonaerense donde aún era posible encontrar un conchabo en el campo daneses.

(1) Entre 1870 y 1930 arribaron al país alrededor de 13.500 inmigrantes R. I., 1996, n.॰ 206 
$\mathrm{y}$, en el mejor de los casos, acceder a una parcela e iniciar una explotación agropecuaria (2).

Conseguir tierras libres donde establecerse y cumplir con el sueño de mejorar la posición socioeconómica haciendo uso de las posibilidades que el país brindaba, no era la única preocupación de los inmigrantes daneses que se establecieron en el centro-sur bonaerense. Restablecer sus vínculos con el pasado, reconstruir su identidad nacional en medio de la sociedad de adopción y transmitirla a las generaciones nacidas en la Argentina mediante la educación formal, fue otra de las expectativas que motivaron al grupo. Aunque si respecto de las preocupaciones económicas que los impulsaban a marcharse más al sur buscando trabajo y tierras libres, el comportamiento fue uniforme en el tiempo; en la importancia atribuida a la preservación de los valores nacionales de la vieja Dinamarca, no reinó plenamente el acuerdo. Las distintas oleadas de migrantes, los cambios en ambas sociedades -la que dejaban atrás y la de adopción- y el liderazgo comunitario de turno, influyeron sobre aquella falta de consenso.

En general, el proceso de reconstrucción de las experiencias y los sistemas de valores daneses tuvo un carácter cambiante en el tiempo. Entre los primeros inmigrantes -los pioneros que llegaron a Tandil en las décadas de 1860 y $1870-$ el apego al pasado fue muy bajo colocando al grupo en los límites del "desarraigo». Se conjugaron aquí una serie de circunstancias entre las que las características de la sociedad receptora: un mundo tradicional y de frontera -que por momentos parecía alçanzar extremos de hostilidad hacia los extranjeros (3)- condicionó en gran medida el virtual «olvido» del pasado. Por su parte, la falta de recursos económicos y la exigua

(2) El acceso de los inmigrantes a la estructura productiva del centro-sur de la provincia de Buenos Aires ha sido analizado en María M. BJERG, "Donde crece el oro. La incorporación de los inmigrantes daneses a la estructura productiva del centro-sur bonaerense, 1848-1930", en Anuario IEHS, 6 (1991), págs. 229-244.

(3) En este aspecto podemos referir el ataque xenófobo de 1871 en el que un personaje conocido como "Tata Dios» encabezó una matanza de extranjeros bajo la consigna de "mueran los gringos y los masones» dejando un saldo de treinta y siete muertos. Sobre el tema es posible consultar, Hugo NA. RIO, Tata Dios, el Mesias de la última montonera. Buenos Aires (1978). 
base demográfica del grupo obstaculizaron la creación de una matriz de instituciones donde pudiera regularse más formalmente la interación social del grupo y reconstruirse su identidad étnica. Los propios inmigrantes, sobre todo comparados con quienes les iban a seguir en la corriente danesa a la Argentina, carecían de serias motivaciones para aferrarse a una cultura y a un pasado que día a día iban volviéndose más lejanos y ficticios. Si bien fueron estos pioneros los que iniciaron el trámite de construir el primer templo luterano del pueblo, para ellos la iglesia solamente cumpliría el rol de dar auxilio espiritual a los creyentes y de brindar los sacramentos a quienes preferían poner sus pies en ella no más de tres o cuatro veces en su vida. Esto era lo que habían aprendido sobre la religión en Dinamarca y nada les hacía pensar que la iglesia debería transformarse en el eje de sus existencias terrenales.

Sin embargo, a fines de los años 1880 las circunstancias comenzarían a cambiar con la llegada de los jutlandeses. Estos inmigrantes traían consigo un conjunto de experiencias virtualmente ajenas a los pioneros de Tandil. Los nuevos aires nacionalistas que comenzaron a correr desde el sur de Jutlandia tras la guerra de 1864, habían enfatizado la importancia de la cultura danesa y del idioma nacional. En una vertiente religiosa que había tenido gran predicamento en la península y se había difundido luego hacia el resto de Dinamarca, la iglesia y las escuelas debían transformarse en un bastión que defendiese la danidad, expresada esencialmente en la lengua y en los valores culturales daneses. Los nuevos inmigrantes se embarcaron en un proyecto de reconstrucción de un pasado que por la fuerza de las circunstancias los primeros habían descuidado. Afortunadamente, el olvido no había logrado hacerse con todo, los primeros daneses habían levantado la iglesia como un espacio devocional para los practicantes y sacramental para los no tan devotos. Los nuevos inmigrantes la transformarían en el eje de la vida comunitaria, atribuyéndole funciones no sólo religiosas sino esencialmente sociales y educativas. Lo que en las décadas de 1860,1870 y parte de la de 1880 era un límite difuso entre el grupo y la sociedad receptora, iría transformándose desde fines de siglo en una línea claramente definida entre el sistema de valores de la comunidad danesa y el de la sociedad en la que estos inmigrantes se disponían a vivir. Línea de defensa de la 
danidad que con el tiempo involucraría también a las generaciones nacidas en la Argentina.

Para los nuevos inmigrantes abocados a una reconstrucción que les permitiera mantener su identidad étnica en la sociedad receptora, el soporte institucional fue crucial. La simple afiliación espontánea en relaciones interpersonales no era suficiente sustento para asegurar la recreación del tejido social tradicional. Era necesario institucionalizar los lazos que vinculaban informalmente a los inmigrantes en función de su común origen para que el grupo se transformase en una comunidad en cuyo ámbito pudiera preservarse una parte de la cultura danesa.

Cuanto más amplia y mejor organizada fuese la matriz de instituciones comunitarias de iglesias, escuelas, sociedades de ayuda mutua, publicaciones, etc., tanto más fácil sería retener las tradiciones culturales y sociales del grupo (4). Esta red institucional que hacía las veces de fundamento de actitudes tan cotidianas como hablar en danés, oír misa de boca de un pastor luterano, cantar los almos de Grundtvig, familiarizar a las generaciones nacidas en la Argentina con los vikingos, las sagas y las monarquías nórdicas, contribuyó a la persistencia de un sistema de valores daneses en medio de la pampa argentina y orientó la dirección de las relaciones que los inmigrantes y sus descendientes establecieron con la sociedad receptora.

La iglesia asumió la responsabilidad de sostener los valores daneses, asegurar la continuidad con el pasado cultural e institucionalizar los vínculos que habían congregado a los inmigrantes. Se transformó en una fuerza centrípeta generadora de una matriz de organizaciones comunitarias que condicionaban en gran medida la dirección de las relaciones interpersonales de los nuevos migrantes y su modo de adaptación a la sociedad receptora.

(4) En este punto coincidimos con la hipótesis vertida por Raymond BRETÓN en "Institutional completeness of ethnic communities and the personal relations of inmigrants», en American Journal of Sociology 70: 2 (1964), pág. 204. 


\section{LA IGLESIA Y LA PRESERVACIÓN CULTURAL}

\subsection{Pietistas y Grundtvigianos}

Antes de analizar el papel de la iglesia y de las escuelas en la interpretación que los inmigrantes daneses hicieron de los valores sociales, culturales y religiosos de su pasado y de los de su nueva realidad, deberemos referirnos a las características del cisma de la iglesia en Dinamarca para poder comprender la influencia que las nuevas ideas religiosas -difundidas sobre todo después de la guerra de 1864- tuvieron en las comunidades de la Argentina y especialmente en la redefinición de sus relaciones con patria de origen.

De un lado se encontraba La Iglesia Unida, también llamada Pietista o Indre Mission, un movimiento que trataba de reavivar las formas tradicionales de la religiosidad tomando a la palabra escrita en la Biblia, a la conversión personal y a la labor misional como sus principales bases. Esta rama de la iglesia era la representante de la versión oficial de la religión luterana danesa y era mantenida por el Estado. Especialmente en los Estados Unidos -donde los daneses se dividieron siguiendo el conflicto de los cismáticos (5)- los pastores misionaban tratando de ganar conversos entre los nativos y entre los otros grupos étnicos. La importancia atribuida al trabajo misional hizo que los pietistas mostraran poco interés por el mantenimiento del idioma y de la herencia cultural danesa, pues en la tarea de convertir y de ganar nuevos adeptos el inglés era más útil (6).

Por otro lado se hallaba La Iglesia Danesa, un ala del luteranismo danés influida por las ideas del predicador, teólogo y salmista N. F. S. Grundtvig (1783-1872). Se trataba de una iglesia libre, de un movimiento de carácter dual donde la identificación con determinadas creencias religiosas sólo tenía sentido

(5) Sobre el cisma de la iglesia danesa en los Estados Unidos ver, Det Danske Selsbakb (ed.), Grundtvig's ideas in North America. Influences and Parallels, Copenhague (1983); Tine WANING, "Danish-American Grundtvigians" en Steffen Elmer JoRgEnSEN et al., (eds.), From Scandinavian to America. Odense (1983); Bredsome Simonsen HENRIK, Kampen om Danskheden. Tro og Nationalitet $i$ det danske Samfund i America. Aarhus (1990).

(6) Thaning KAJ, N.S.F. Grundtvig. Odense (1972) págs. 16-19.

R. I., 1996, n. 206 
en su relación con los valores culturales del pueblo danés. Marcado por las influencias del Romanticismo, el principal objetivo de la prédica de Grundtvig en el aspecto cultural era el de apercibir a los daneses de su danidad (Danskheden), pues el predicador sostenía que hasta tanto el pueblo no lograra descubrir su propia identidad, Dinamarca no podría florecer como país.

Las ideas del movimiento grundtvigiano fueron difundidas desde los Folkehojsköler (Colegios Superiores Populares), centros de educación para adultos adonde asistían especialmente campesinos y trabajadores rurales. El primero de estos colegios fue creado en 1844 por el propio Grundtvig en Sorö, al sur de Jutlandia, motivado en parte por la necesidad de reforzar el sentimiento patriótico local en una fase de creciente desarrollo de la conciencia nacional germana que terminaría en la guerra del 1864. A esta institución siguieron otras como la de Rödding, fundada especialmente para la lucha por la nacionalidad en el territorio sur de Jutlandia, especialmente después de que el alemán fue reconocido como lengua oficial en el Consejo de Schleswig (7). Los principios ideológicos impartido en estos colegios otorgaban una importancia central al idioma danés al que consideraban una "fuerza vital» a través de la cual se definía el espíritu de una nación. La unidad de un pueblo consistía no solamente en compartir una herencia biológica sino en el establecimiento de un acuerdo general sobre la preferencia de vivir en su patria y de hablar su lengua materna. Ambos eran la esencia del Folkelighed (de la herencia etno-cultural nacional) y debían ser colocados en la máxima jerarquía del sistema de valores.

La gran difusión del grundtvianismo y de los folkehöjskoler tuvo lugar después de la derrota de Dinamarca frente a Prusia en 1864. La posguerra había sometido al dominio alemán a más de 150 mil dano-parlantes. Ante estas circunstancias Grundtvig sostuvo que el límite entre Dinamarca y Alemania no podía seguir otra línea que la lingüística. Los Colegios Superiores Populares concentraron sus esfuerzos en la tarea de sacar al pueblo danés de su sentimiento de derrota y apatía para preparar el camino de la reunificación de los territorios perdidos, que

(7) Det DansKe SElSKab (ed.), The Danish Folk High Schools. Copenhague (1980), págs. 24-27. 
tuvo lugar recién en 1920. Desde el sur de Jutlandia el núméro de colegios comenzó a crecer y a difundirse hacia el resto del país (8).

En los años que siguieron a 1864, el grundtvinismo adoptó el carácter de un movimiento nacional y cristiano que se manifestaba mediante la creación de congregaciones voluntarias donde, a diferencia de los pietistas, la relación entre la iglesia y el Estado quedaba virtualmente anulada, ya que los propios feligreses asumían la responsabilidad de sostener económicamente a sus parroquias.

Tras la desaparición física de Grundtving sus herederos continuaron con el movimiento y lo expandieron hacia los Estados Unidos, donde también definieron su postura respecto al problema de la asimilación de los inmigrantes daneses en Ultramar. Los miembros del movimiento sostenían que era posible cambiar de país, pero mientras se ha nacido en un pueblo no había modo de dejarlo ni siquiera moviéndose de un extremo del mundo a otro. El solo hecho de intentar algo semejante era considerado un pecado. De esta forma los daneses de la pradera americana que comulgaban con las ideas del Grundtving iniciaron una tarea de reconstrucción de su Danskheden (danidad), basada en la acción de iglesias y escuelas -especialmente Folkehöjskoler- que trataban de potenciar la importancia del idioma y del sistema de valores daneses.

\subsection{Las congregaciones de la Argentina frente al cisma}

Las congregaciones danesas de la Argentina no reprodujeron el cisma de la iglesia danesa del modo en que lo hicieron sus pares en los Estados Unidos y ni siquiera sostuvieron una explícita pertenencia a cualquiera de las dos alas en las que se dividía la iglesia luterana de Dinamarca. Algunos autores hacen referencia a la presencia de ciertas inclinaciones en favor de una u otra tendencia en las diversas congregaciones que conformaron la comunidad danesa. Bela Lesko, por ejemplo,

(8) En 1870 había 52 Folkehöjskoler y en la década de 1890 la cifra había llegado a 75 en todo el país -aunque la amplia mayoría estaba en Jutlandiaen tanto que el número de alumnos se había duplicado.

R. I., 1996, n.० 206 
destaca la preeminencia del grundtvianismo en Tres Arroyos, donde funcionó el primer Folkehöjskole (Colegio Superior Popular) sobre el modelo de las tantas instituciones de este tipo que fueron fundadas en Dinamarca y en los Estados Unidos para difundir las ideas religiosas y el estilo de vida cristiano que proponía Grundtvig. Mientras que caracteriza a Necochea como más inclinada al indre-missionismo (9). Pero esto tiene que ver, sobre todo, con la formación de los pastores a cargo de las congregaciones, con las tradiciones de los inmigrantes que las conformaron y con las características del grupo y de su relación con la sociedad receptora. Esta situación se advierte claramente en la iglesia de Tandil, sobre todo durante los años en que se formó la matriz de instituciones que serviría de base a la comunidad.

Después de la fundación de la iglesia en 1877, el pastor Oscar Meulengracht, un graduado en teología de la Universidad de Copenhague y miembro oficial de la iglesia de Dinamarca, se hizo cargo de la congregación (10). Al cabo de algo menos de seis años, Meulengracht regresó a su país. Durante este tiempo no hubo ningún esfuerzo claro - de parte del pastor o de los feligreses- por preservar los vínculos culturales con el pasado danés. Como afirmamos más arriba, la mayor parte de los inmigrantes daneses que vivían en Tandil provenían de la isla del sudeste de Dinamarca donde el movimiento grundtvigiano no había alcanzado demasiada difusión a pesar de la existencia de un colegio superior popular en la isla de Lolland en la década de 1870. De todas formas su visión de la religión seguramente seguía siendo la que tradicionalmente había primado en Dinamarca y que estaba en plena vigencia cuando abandonaron el país los pioneros de principios de los años sesenta del siglo pasado. Hasta bien entrada la década de 1880, en Tandil pocos demostraban interés en mantener una identificación nacional con Dinamarca preservando el idioma o la cultura del pasado.

(9) Referencia tomada de Dybdal MöLLER ERIK, National og konffesional egenat paa latinamerikanske premisser. Forholdet melles de danske menigheder og andre lutherske menigheder og kirke i den ketolske kultursammenhaeng $i$ Argentina. Tesis de Licenciatura en Teología, Universidad de Aarhus, Aarhus (1986), en mimeo.

(10) Kaekhöj Lars, Danske i Argentina. Copenhague (1948), pág. 136. 
Más allá de las necesidades religiosas satisfechas en el seno de una iglesia luterana, la mayoría sostenia la importancia de realizar un esfuezo para adaptarse a la vida, la lengua y las costumbres de la sociedad de adopción.

Cuando Meulengracht se marchó la iglesia debió permanecer cuatro años sin ministro, después de los cuales la congregación recibió a Niels Dael. A diferencia de Meulengracht, Dael no era un teólogo sino un pastor que había obtenido su educación en el sur de Jutlandia, en Askov Höjskole (Colegio Superior de Askov), uno de los centros educativos del grundtvianismo donde, entre otras cosas, se preparaba a quienes se harían cargo de las congregaciones danesas asentadas en los Estados Unidos para asumir la responsabilidad de transformar a las iglesias en bastiones de defensa de la danidad. Junto a él llegaron a Tandil algunos maestros que el pastor había conocido en Askov y en la zona de Mors, en el norte de Jutlandia, donde el grundtvianismo y las congregaciones libres habían alcanzado gran difusión. Durante los diez años que Dael estuvo a cargo de la congregación se plasmó un modelo cuyas preocupaciones no sólo eran la prédica y la labor teológica sino, sobre todo, la construcción de un tejido social comunitario que tuviera como base los valores de la cultura danesa y la formación de las nuevas generaciones en aquellas tradiciones. El pastor y sus compañeros se abocaron a la labor de fomentar una educación que debía no sólo instruir a los menores, sino también contribuir a la preservación del idioma y del legado cultural danés (11). Al tiempo que la congregación adoptaba este nuevo perfil, la corriente migratoria iba incorporando cada día más gente proveniente de los distritos del centro y norte de Jultandia y de Copenhague, en detrimento de la vieja migración de las islas del sudeste del país. Estos nuevos inmigrantes habrían sido influidos, en mayor o menor grado, por los nuevos vientos nacionalistas que soplaban en Dinamarca. Poco a poco las ideas de los pioneros que preferían adaptarse a la nueva realidad y esa misma realidad irían cambiando. De un ambiente tradicional y

(11) Baekhöj LARS, [10], pág. 165; Ibidem, «Lidt om dem Danske Skole i Tandil", en Aarsskrift for Dansk Skoleforening for Tandil og Omegn. Tandil (1908), págs. 5-16; Johansen OLuf, Johannes og Katrine. En sandfaerdig fortaelling fra Danmark og Argentina. Eldorado (1944), cap. 7. 
rayano con la hostilidad se pasaría a un mundo modernizado y, en parte, más permisivo con los extranjeros, muy especialmente con estos rubios agricultores noreuropeos que encajaban a la perfección en el modelo alberdiano de inmigrante deseable. Por su parte, los isleños serían fagocitados por la nueva oleada de jutlandeses y copenagueses que, sin instaurar formas idénticas a las congregaciones grundtvigianas de los Estados Unidos, sellarían el perfil que iba a adoptar la inserción de los inmigrantes en la nueva sociedad más allá de las circunstancias afiliaciones de sus integrantes.

Un buen ejemplo de lo que afirmábamos anteriormente es lo que ocurrió en 1898 cuando un nuevo pastor, Th. Andresen, se hizo cargo de la iglesia de Tandil. Al igual que Meulengracht, era un teólogo graduado en la Universidad de Copenhague que dentro del cisma de la iglesia danesa se encontraba mucho más cerca del indre-missionismo que de las ideas de Grundtvig (12). No obstante eso, la suerte de la congregación había sido definida en los diez años que duró la prédica de Dael y la tarea de su círculo de conocidos de Askov y Mors. Las bases de la matriz de instituciones que conformarían una comunidad celosa de su idioma y de sus tradiciones culturales habían sido creadas. Otros pastores y maestros se sucederían con el tiempo para hacerse cargo de los destinos de la comunidad, su filiación a una u otra ala de la iglesia danesa sería claramente advertida por los fieles, pero nunca suficiente para generar un cisma al estilo de los Estados Unidos o para inclinar definitivamente a la congregación en favor de una u otra tendencia.

De manera que hacia fines de 1880 los daneses de la Argentina adoptaron tácitamente los principios del grundtvianismo. Lejos de lo que sostenían los primeros inmigrantes respecto a las necesidades de aprender el idioma, los códigos culturales y los valores de la nueva sociedad, prefirieron levantar un muro alrededor de la comunidad y vivir como en Dinamarca mirando de lejos una realidad que, tarde o temprano, erosionaría ese muro, pero que, por entonces, les era lejana e incomprensible. Está claro que muchos de los inmigrantes sabrían sólo superficialmente de las discusiones reinantes en el interior de la igle-

(12) Baekhöj LARs [10], pág. 145. 
sia danesa, pero la realidad hizo que, unos de manera consciente y la mayoría porque las circunstancias así los exigían se inclinaran hacia las ideas grundtvigianas y crearan una lille Danmark (pequeña Dinamarca) al otro lado del mundo como el camino más largo, pero también menos traumático en un proceso de adaptación a la sociedad argentina.

La iglesia fue el eje en la formación y el mantenimiento de la vida comunitaria. A medida que los asentamientos iban expandiéndose hacia el sur se creaban nuevas congregaciones, como la de Tres Arroyos en 1901 y la de Necochea en 1918. Las congregaciones contaban con una importante masa de afiliados que, además de pagar regularmente sus contribuciones, participaban de las múltiples actividades surgidas desde el seno de las instituciones religiosas (13). La iglesia se transformó en un gran techo que amparaba a otras organizaciones comunitarias donde se desarrollaban actividades educativas, sociales y culturales. Desde las congregaciones se fundaban escuelas, bibliotecas, asociaciones de lectura, entidades de ayuda mutual, sociedades de canto, etc., que permitieron que, lo que en los primeros años de la inmigración danesa en Tandil fue un ámbito

(13) Confrontando la cédula del Segundo Censo Nacional de Población de 1895 con una lista de los miembros que pagaron su aporte a la Congregación Luterana Danesa de Tandil (única existente en el país de ese entonces) en el período 1894-1895, pudimos observar que 64 por 100 de los hombres adultos contabilizados por el censo eran miembros de la iglesia. En general, era el cabeza de familia quien realizaba el pago de las cuotas. Solían existir casos de mujeres que efectuaban un aporte paralelo al de sus esposos pero, en general esto no era demasiado frecuente. Otros casos algo más comunes eran los pagos realizados por las viudas y sus hijas adultas solteras o, directamente por mujeres solas. En el período 1894-1895 contribuyeron solamente 22 mujeres que representaban el 25 por 100 de las censadas. Realizamos un cálculo similar con los datos que nos provee el Tercer Censo Nacional de Población de 1914. En este caso no pudimos separar a los hombres adultos de los menores de la comunidad. Por lo cual los porcentajes, que en general son inferiores a los registrados en 1895, tienen algún sesgo. La relación entre los sexos en las contribuciones a la congregación de Tandil cambió en favor de una mayor participación de las mujeres en las listas de pagos a la iglesia. En 1914 había 81 mujeres danesas en Tandil, un 60 por 100 de las caules eran miembros de la congregación, en tanto que la participación de los varones, que sumaban 329 en todo el partido según los datos censales, era sólo de 49 por 100. Desafortunadamente no contamos con datos que nos permitan realizar este mismo cálculo para la Congregación Protestante del Sur con sede en Tres Arroyos, la que había comenzado a funcionar en 1901.

R. I., 1996, n.o 206 
para la devoción y los sacramentos, en torno al cambio de siglo, se transformase en el vehículo que impulsaba la recreación del sistema de valores nacionales daneses y que regulaba el proceso de adaptación de los inmigrantes y sus generaciones a la sociedad receptora.

Además, el rol socializador de la iglesia se multiplicaba debido a que ésta adoptó un carácter diferente del que tradicionalmente había tenido en Dinamarca donde si bien, como mencionamos anteriormente, existían frimenigheder (Congregaciones libres o voluntarias) cuyos fieles aportaban los emolumentos necesarios para mantener a los pastores y a las parroquias, en general, el Estado se hacía cargo de soportar económicamente la vida religiosa de los ciudadanos (14).

En la Argentina los feligreses eran el principal soporte económico de las iglesias y sus pastores, de modo que las congregaciones dejaron de ser núcleos de fieles que se reunían exclusivamente para la prédica y el servicio, al compartir un nuevo cometido: el de trabajar en pos de la supervivencia de sus instituciones religiosas. Esto daba lugar al desarrollo de una intensa vida social. Las comisiones encargadas de juntar fondos para pagar el salario de los pastores y para mantener a la iglesia organizaban fiestas, obras de teatro y bazares donde concurría el conjunto de los miembros de la comunidad. Las damas de la congregación preparaban comidas típicas que eran vendidas en estas reuniones, los jóvenes amenizaban el encuentro demostrando sus destrezas en los bailes folclóricos de la lejana patria de sus padres y los hombres se encargaban de organizar la infraestructura de estos bazares que solían prolongarse durante dos o tres días (15). Las congregaciones tenían varias reuniones de esta índole en los distintos asentamientos a lo largo del año. Esta costumbre resultaba en una nutrida agenda social motivada por la necesidad de mantener vivo el vínculo cultural con el pasado. En estos festejos la gente de los distintos núcleos daneses del centro-sur bonaerense se encontraba, allí se intercambiaban información, noticias de Dinamarca, se conocía a los nuevos inmigrantes y los jóvenes

(14) Dybdal MöLLER ERIK, [9], pág. 26.

(15) Entrevista con Sofus Kastrup, Tandil, 19 de julio de 1993. 
comenzaban los cortejos que culminaban en casamientos endogámicos (16).

La iglesia danesa de la Argentina adoptó el carácter de una típica frimenighed. Lo que había sido una excepción a la tradicional unidad de Iglesia y Estado se volvió por necesidad una regla en la vida interna de las congregaciones de la pampa. Los feligreses no tenían otra opción que asumir la responsabilidad de mantener económicamente el restablecimiento de sus creencias y valores. De modo que, una vez más, la filosofía de los círculos grundtvigianos se adecuaba mejor a las características del grupo y de su relación con la sociedad de adopción.

Como institución religiosa, la iglesia permitió la recreación de la vida devocional de los daneses en un medio católico y como órgano social, se transformó en el centro alrededor del cual los inmigrantes pudieron reunirse para vencer la soledad y el aislamiento, pero también para revivir el patrimonio cultural danés, separado por un infranqueable abismo con el sistema de valores reinantes en la sociedad receptora. De este modo quedaba resuelto el problema de la adaptación de la primera generación a la nueva realidad. Las actividades desarrolladas desde la iglesia condicionaban en gran medida la dirección de sus relaciones con la sociedad nativa y con la propia comunidad. Sin embargo, esto no era suficiente. La iglesia fijó en la mira a las generaciones nacidas en la Argentina. Si la energía, el tiempo y los recursos económicos que se habían invertido en organizar social e institucionalmente al grupo no querían dilapidarse, era necesario reproducir los valores culturales y sociales daneses en la educación de los hijos y nietos de los inmigrantes. De otro modo, no existiría reaseguro a la permanencia de la danidad más allá de la vida de la primera generación nacida en Dinamarca. La escuela se transformó en la hija dilecta de la iglesia desde allí se harían esfuerzos denodados por preservar el idioma y las tradiciones de un país que muchos de los miembros de la segunda y tercera generación jamás llegarían a conocer.

(16) Anuncios de fiestas en distintos diarios de la comunidad; programas de fiestas encontrados en el archivo de la congregación de Tandil; Baekhöj LARS (1948), [10], pág. 172 y sigs. donde el autor describe una de las reuniones tradicionales de los asentamientos daneses realizada anualmente (desde 1923 hasta la actualidad) en Cascallares, partido de Tres Arroyos, llamada "Los ocho días en el Colegio Superior».

\section{R. I., 1996, n. 206}




\section{Preludio de una nUeVa identidad. Las escuelas DE LA COMUNIDAD}

A medida que el grupo danés iba tomando forma y dejaba de ser un núcleo de trabajadores adultos para transformarse en una comunidad estable de familias, las necesidades de instrucción de los menores se hacían notar cada vez más. Lo que había sido un simple intento informal de impartir una educación rudimentaria y asistemática al amparo de la iglesia y de la fe luterana, se fue volviendo un sistema educativo comunitario a cargo de los pastores y maestros especialmente traídos desde Dinamarca para hacerse cargo de la instrucción de la segunda generación.

Hasta mediados de la década de 1880, la inmigración era poco significativa y los pioneros nucleados en torno al pueblo de Tandil constituían un grupo pequeño que luchaba con un ambiente nuevo, primitivo y en ocasiones hostil. Tratar de difundir sus pautas productivas agrícolas en una zona donde la ganadería era la actividad económica reinante, vivir pendientes de que el ganado no avanzara sobre los sembrados llevándose en una noche el trabajo de meses, adaptarse a un ambiente social, religioso y político desconocido, era una tarea ciclópea que demandaba gran esfuerzo. La idea de fundar una iglesia fue un sueño acariciado desde los años 1860, pero obstaculizado por la carencia de recursos económicos debida, sobre todo, al escaso número de miembros que conformaban el grupo.

En las reuniones dominicales que este puñado de daneses realizaban en la casa de Juan Fugl -el pionero que trajo al primer núcleo desde Dinamarca- la idea de tener una iglesia luterana se había vuelto recurrente. Los curas católicos del pueblo no veían con buenos ojos a estos blondos protestantes y se lo demostraban claramente negándose a bautizar a sus hijos, a bendecir sus bodas y a dar cristiana sepultura a sus muertos que, a falta de una mejor alternativa, descansaban en paz a un costado de la quinta de Fugl (17). Sin embargo, como afirmabamos anteriormente, la creación de una institución religiosa tenía poco que ver con los intentos de preservar en su seno el

(17) Fugl Hans, Memorias traducidas por Alice LARSEN Rabal, Tandil (1989), pág. 310. 
pasado y de recrear formas que permitieran mantener vivo el espíritu danés en las generaciones nacidas en la Argentina. En este punto son muy elocuentes las afirmaciones de Fugl respecto a lo que ocurría años antes de su regreso definitivo a Dinamarca en 1875, cuando aún faltaba tiempo para que llegase el primer pastor grundtvigiano y su grupo de conocidos de Askov y de las congregaciones libres del norte de Jutlandia a hacerse cargo de la educación de los menores de la congregación:

"Con respecto a la instrucción de los niños daneses no veía en el presente ni en el futuro ninguna dificultad, ya que había en Tandil buenas escuelas para niñas y varones, iguales que las primarias en Dinamarca. Y aunque pudiera ser agradable tener un maestro de idioma danés, creo que para los niños y la juventud era mucho más provechoso adquirir conocimientos en el idioma del lugar que luego en su vida necesitarían diariamente» (18)

Sin embargo, estas expresiones referidas a los primeros años del asentamiento no tendrían demasiado eco en un futuro cercano. Durante la segunda mitad de los años 1880 el tema de la educación comenzó a preocupar a los miembros de una congregación. Por ese entonces la iglesia no sólo impulsó la contrucción de una escuela sino que introdujo la discusión acerca de qué carácter debía tener la educación que allí se impartiera.

Las contribuciones económicas de los miembros de la congregación constituyeron los únicos recursos con los cuales se construyó la escuela. Esta situación se reiteraría en el siglo siguiente, cuando los agricultores daneses de Tres Arroyos y de Lumb -en el partido de Necochea- levantaran sus propios colegios contribuyendo con cinco pesos por fanega de trigo cosechada al fondo de sus respectivas congregaciones. En este sentido es importante destacar que los miembros del grupo colaboraron ampliamente no sólo con la fundación de los colegios sino, sobre todo, con el mantenimiento de los mismos, repitiendo la experiencia que habían impuesto las necesidades de soportar económicamente a la iglesia. Tanto en Tandil cuanto posteriormente en Tres Arroyos y Lumb fueron creadas asocia-

(18) Ibidem, pág. 354 .

R. I., 1996, n. ${ }^{\circ} 206$ 
ciones al estilo de las actuales cooperadoras escolares que, con la contribución anual de sus integrantes, ayudaban a la continuación de las labores educativas y a la creación de fondos de becas de estudio para los menores de escasos recursos. Estas asociaciones no estaban compuestas exclusivamente por los padres de los alumnos sino que las congregaciones en su conjunto asumían la responsabilidad de mantener económicamente el funcionamiento de las escuelas. En los años previos a la fundación del colegio danés de Cascallares, Tandil tenía la única escuela del grupo y su asociación llegó a contar con cerca de quinientos miembros, cifra que se redujo a algo menos de la mitad en la década de 1920, cuando la comunidad tenía tres entidades educativas (19).

Por estas alturas pocos se planteaban cómo debía ser la educación de sus hijos. Con algunas variaciones, los otros asentamientos daneses siguieron el modelo cuya principal impronta fue sellada por el pastor Dael y su grupo de compañeros de Askov y Mors en la escuela de Tandil. La transmisión de la herencia cultural danesa fue el eje en torno del cual giraría la instrucción de los menores. Pero la mayoría de esos niños había nacido en la Argentina y también debería aprender la cultura, las tradiciones y el idioma del país que sus padres habían adoptado. La forma de compatibilizar estos dos sistemas de valores que se interferían continuamente, fue un tema de discusión recurrente en las congregaciones.

Hacia fines del siglo pasado, la escuela danesa de Tandil adoptó una forma de organizar la educación que permanecería, con sutiles modificaciones hasta a fines de la década de 1940. Para empezar a resolver el escollo de educar hijos de padres daneses y luteranos en un país católico e hispanoparlante se incorporó al plantel docente a un maestro argentino, exigencia que, por otra parte, el consejo escolar no dejó de remarcar y que una ley de 1917 transformó en condición indispensable para permitir el funcionamiento de escuelas étnicas (20). En este punto, los daneses temían perder la libertad de impartir un tipo de instrucción donde Dinamarca y su cultura se ubica-

(19) Baekhöj LaRS [10], pág. 168; Lista de contribuyentes al Dansk Skole Forening i Argentina (1916 y 1928).

(20) Aarsskrift for Dansk Skole Forening i Argentina (1917). 
ban en el centro de los esfuerzos educativos. Sistemáticamente, las autoridades de la escuela se negaron a obtener financiación estatal para pagar los sueldos de los maestros argentinos y se reservaron el derecho de contratarlos sin intermediación del consejo de educación (21).

Debido a que la iglesia tenía como uno de sus principales objetivos la preservación del idioma, el currículum de la escuela fue organizado de modo tal que los niños debieran permanecer interminables horas reforzando la lengua en la que a diario se comunicaban con sus padres. Un 60 por 100 del tiempo que entre lunes y sábado los niños dedicaban a la escuela era empleado en estudiar la historia, la geografía, la religión y el idioma de Dinamarca. Las exigencias del programa oficial de la educación pública argentina, obligaban a los estudiantes a volver por la tarde al colegio para oír otra lengua y conocer otros accidentes geográficos, introducirse en una nueva cultura y aprender a respetar a los prohombres que habían construido su nueva patria mucho después que Valdemar Sejr o Christian IV.

A pesar de que una parte importante de la instrucción no sólo se realizaba en castellano sino que se refería directamente a la cultura hispana y a los valores de la nueva sociedad, los mayores esfuerzos eran destinados a recrear un sentimiento nacional danés y una identificación religiosa evangélica luterana en los miembros de las generaciones nacidas en la Argentina. Además de la utilización de programas de estudio y de literatura empleada por las escuelas primarias de Dinamarca, que en materia como Historia o Historia de la Iglesia contribuían a inculcar en los menores elementos que conducían a la formación de una identificación con la tierra de sus padres, el resta-

(21) Ibidem (1919 y 1927): En el caso del colegio danés de Cascallares la actitud frente a la intervención del Estado en la educación impartida en castellano, parece más flexible que la adoptada en Tandil. De hecho, ante la necesidad de reemplazar una maestra argentina que se había desempeñado durante cinco años en el mencionado colegio, el propio presidente de la Comisión Directiva de la Congregación sostuvo que, por tratarse de un docente de castellano, el colegio debía dirigirse al Consejo escolar, pues era el Estado quien tenía la obligación de resolver el problema. Congregación Protestante del Sur, Tres Arroyos, Acta de la Asamblea General Ordinaria del 24 de febrero de 1924

R. I., 1996, n.o 206 
blecimiento del calendario tradicional que respetaba las festividades patrias y religiosas danesas fue otro signo importante de los esfuerzos realizados en aquella dirección. Además de las tradicionales festividades del 25 de mayo y el 9 de julio, celebrados al amparo de dos banderas y dos himnos, la escuela recordaba cada 5 de junio el día de la Constitución de Dinamarca, el onomástico real era celebrado anualmente y se guardaban las tradiciones luteranas en las celebraciones de la Pascua, Pentescostés, el día de la Ascensión y la ceremonia del árbol de Navidad. Todos los noviembres la escuela organizaba una fiesta de fin de curso a la que llamaban Skovtur y que hacía las veces de una celebración tradicional en el calendario campesino escandinavo. Tan bien captada por Bille August en su película Pelle Erobreren, en la imagen de las carretas adornadas con flores y banderas transportando hacia el bosque a ufanos campesinos dispuestos a beber, cantar y bailar hasta el rojizo anochecer nórdico, el Skovtur era una "salida al bosque" que encerraba un sentido comunitario y que los agricultores realizaban después de terminada la mies. Rescatando ese componente comunitario, la escuela organizaba excursiones similares antes de finalizar el año escolar (22).

Por otro lado, la creación de una identificación con los valores culturales argentinos de parte de los maestros nativos y el uso del castellano, no sólo entre las generaciones nacidas en la Argentina sino su cada vez más difundido empleo entre los inmigrantes en sus relaciones con la sociedad receptora, fueron generando un sentido de pertenencia de los miembros de la comunidad a su país de adopción. Esto se advierte en la participación de la escuela y de la congregación en las celebraciones del Centenario de la ciudad de Tendil en 1923. Los alumnos, haciendo gala de las banderas de sus dos patrias, desfilaron para honrar al General Martín Rodríguez (fundador de Tandil). La congregación ofrendó al pueblo dos valiosos jarrones de porcelana danesa diseñados en Copenhague a propósito de la ocasión y el pastor Andresen, por entonces ministro de la iglesia y director de la escuela, se dirigió a los vecinos de

(22) Los datos sobre el calendario escolar y los planes de estudio han sido tomados de diversos números de los anuarios de las escuelas de Tandil y Cascallares en el partido de Tres Arroyos, entre 1908 y 1932. 
Tandil en un discurso que destacaba un sentimiento de pertenencia y una estrecha vinculación de la comunidad a la historia y al desarrollo de las ciudad:

«...setenta años atrás, este pueblo se hallaba en sus albores llego Juan Fugl, el primer colono danés al que seguirían miles de compatriotas atraídos por la libertad de esta tierra (...) somos de un país de agricultores y de bosques y ese ha sido nuestro legado a esta nación, fuimos los primeros en labrar la tierra y en plantar árboles (...) Después de Buenos Aires, Tandil es la ciudad sudamericana mejor conocida en Dinamarca (...) Nombres como Juan Fugl, Manuel Eigler, Poul Christiansen (...) serán escritos en la Historia de Tandil y ya lo están en los anales de este municipio» (23).

Sin embargo, la comunidad aún se hallaba lejos de la aculturación. Su interacción con la sociedad nativa se limitaba mayormente a relaciones de tipo secundario vinculadas, sobre todo, a los aspectos laborales o económicos y ocasionalmente a situaciones como la que hemos descrito más arriba, en tanto que las relaciones sociales primarias tenían lugar casi exclusivamente dentro del grupo (24).

En su clásico estudio sobre la asimilación a la vida americana, Milton Gordon sugirió que el cambio social y la adaptación se desarrollan por etapas, comenzando con la aceptación de un conjunto de valores culturales más amplios que no amenazan directamente a la existencia del grupo. Los daneses se encontraban en este estadio, al que Gordon denominó "asimilación cultural", y pasaría aún mucho tiempo hasta que el grupo se abriera a mantener relaciones sociales primarias con el mundo exterior aceptando, por ejemplo, que sus hijos concurrieran a

(23) Aarsskrift for Dansk Skoleforening i Argentina (1923), pág. 39.

(24) El grupo contaba, no sólo en Tandil, sino en el resto de asentamientos, con un importante número de institucines que satisfacían necesidades sociales y culturales de sus miembros. Entre otras, había dos sociedades de lectura que contaban con una nutrida biblioteca de literatura universal publicada en danés, tres clubes, dos asociaciones de jóvenes con fines religiosos y deportivos que nucleaban a los hijos de daneses nacidos en la Argentina, dos compañías de teatro que representaban obras de autores daneses, una entidad de ayuda mutual que funcionaba en Buenos Aires desde 1892 y dos cajas de seguros para enfermedad, accidente en Tres Arroyos y Tandil, etc. 
la escuela pública, fueran educados en la fe católica o rompiesen las pautas matrimoniales endogámicas para casarse con nativos o con otros extranjeros (25).

Los inmigrantes y sus hijos vivían el proceso de adaptación a la nueva realidad de una manera diferente. La primera generación planteaba recurrentemente su temor a ser fagocitada por la sociedad de adopción y a perder de ese modo su Danskheden (danidad), un indefinible sentimiento de identificación con unos valores culturales y sociales que habían soportado el cruce del océano, pero no sin consecuencias. Debilitada ante la contundencia de una realidad tan diferente, requería un esfuerzo denodado mantener la danidad en medio de la pampa argentina, esfuerzo que también involucraba a la segunda generación.

«La pregunta que casi naturalmente surge (...) es la de permanecer siendo daneses o entregarnos a que el tiempo nos vuelva argentinos y si debemos tener una educación danesa o una argentina (...) La colonia se volverá seguramente argentina, pero hagamos esfuerzos para que eso ocurra lo más lentamente posible! (...) a causa de la migración de sus padres, la segunda generación ha perdido su capacidad de experimentar la cultura y el espíritu daneses y aún no han podido establecer sentimientos claros hacia la cultura y el espíritu nacional argentinos (...) no son ni totalmente daneses ni completamente argentinos» (26).

La escuela debería encargarse de la tarea de recrear aquel espíritu nacional danés que las generaciones nacidas en la Argentina no estaban en condiciones de experimentar directamente. Recreando un Danskheden imaginario, la educación serviría entre otras cosas para impedir que la comunidad fuese fagocitada por la sociedad argentina. Pero a nadie podía escapar que los niños eran argentinos, que su idioma era el español y que estaban mucho más cerca del espíritu y de la cultura argentina que de la patria de sus padres. Cómo com-

(25) Gordon Milton, Assimilation into American Life. New York (1964), Caps. 3, 4, 5 y 6 .

(26) Pedro Delmar; "Andet Slaegtled", en Aarsskrift for Dansk Skoleforening $i$ Argentina (1915), págs. 7-8. 
patibilizar el legado cultural danés con el nuevo sistema de valores en el que, aunque nadie lo reconocía claramente, los menores se hallaban fuertemente involucrados, fue la preocupación central de la iglesia y la de escuela danesa.

Los argumentos a favor de una educación desarrollada en el seno de la comunidad fueron de variado tenor. Algunos tuvieron como preocupación central el rol de la fe católica en la escuela argentina, sosteniendo que los niños que tenían padres protestantes, que habían sido bautizados en la iglesia luterana de la comunidad y que en el futuro confirmarían las creencias de sus mayores en el seno del protestantismo, no podían ser alegremente entregados a una educación liderada «por curas y monjas» (27). Otros argumentos giraron en torno a la calidad de la educación y del material didáctico traído desde Dinamarca. Los más extremos sostenían que la educación danesa era muy superior a la Argentina (28). En tanto que los moderados opinaban que la instrucción impartida siguiendo el modelo de las escuelas primarias de Dinamarca se adecuaba mejor a la naturaleza de los niños -tácitamente diversa de la de los menores nativos-, pero que esto no significaba que la escuela argentina fuese de calidad inferior o que los menores educados en los valores de Dinamarca fueran a ser peores ciudadanos argentinos en el futuro (29).

Que el carácter de la educación era una preocupación permanente se advierte con claridad en la notable cantidad de escritos que sobre el tema aparecían en los periódicos de la comunidad (30) y en el Aarskrift for Dansk Sokoleforening, un anuario publicado por las escuelas de Tandil y Cascallares -en

(27) Juan ANDERSEN, "Skolen i Tandil», en Aarsskrift for Dansk Skoleforening $i$ Argentina (1919), pág. 10.

(28) Pedro Delmar, [26], pág. 13; J. Sommer, "Til Foraeldrene af Skolepligtige Born", en Aarsskrift for Dansk Skole Forening i Argentina (1919), păgs. 21-23.

(29) Juan ANDERSEN, [27], pág. 10.

(30) En 1889, uno de los periódicos de la comunidad, el Tandils' Tidende, publicó una serie de artículos donde los daneses de Tandil polemizaban respecto a la necesidad de mantener una escuela étnica, y una educación donde los menores eran instruidos en danés y se les enseñaba a identificarse con los valores de un país que les era extraño. Sin embargo, sólo la minoría estaba a favor de enviar a los niños a las escuelas públicas argentinas y a favorecer, de ese modo, su integración en la sociedad argentina.

\section{R. I., 1996, n. 206}


el partido Tres Arroyos- donde, además de informar sobre el funcionamiento de la institución y el estado de sus recursos económicos, se transcribían conferencias de alguna visita destacada, se escribían artículos sobre la vida de determinados personajes sobresalientes en la historia del grupo o sobre temas que seguramente despertaban polémica, como el uso del idioma danés, el rol de los maestros daneses, el papel de la educación a domicilio, etc.

Algunos de los planteos vinculados al perfil que debía adoptar la educación en la escuela de la comunidad se basaban en razones más sólidas que otros que sólo sostenían que Dinamarca era una nación superior, reconocida por su cultura y que esto se debía al carácter de una educación que tenía que ser completamente trasplantada a la Argentina (31). Entre los primeros se encuentran por ejemplo, el argumento del maestro Baekhöj, un hijo de inmigrantes que llegó a temprana edad con sus padres a Tandil y que obtuvo su preparación superior en el colegio grundtvigiano de Askov, al sur de Jutlandia. Su preocupación central era la del peso que debía otorgarse a los valores de la danidad y a los de la argentinidad en la instrucción de los menores, en el sentido de que ambos sistemas mantenían una lucha permanente.

"Valdemar el Grande se había casado en su juventud con Tovelille simplemente porque estaba enamorado de ella. Sin embargo, cuando llegó a ser rey se casó con Sofie por prudencia y comenzó entonces una lucha permanente no sólo entre sus dos esposas sino también en el corazón del propio rey. El amor lo atraía hacia Tovelille y el deber hacia Sofie, a su manera, el joven rey amaba a ambas. Creo que este sentimiento es bien conocido entre los inmigrantes que aquí vivimos. Nuestro corazón quiere volver por amor a Dinamarca, sin embargo, por prudencia sabemos es mejor permanecer en la Argentina. Pero la historia que estoy contando no terminó allí. La disputa entre las dos esposas finalizó el día que Sofie mató a Tovelille. Y en la lucha de los inmigrantes va a pasar algo parecido. Llegará el día en que la prudencia obtenga su victoria sobre los dictados del corazón y entonces sobrevendrá la calma» (32).

(31) J. SoMmer, [28], pág. 22.

(32) Baekhöj LARS, "Lidt om Skolehold i Argentina», en Aarsskrift for Dansk Skoleforening i Argentina (1911), págs. 36-37. 
Lo que más preocupaba al maestro era la reprodución de esta contienda en el seno de la escuela. Transmitir a los niños el espíritu de la lejana patria de sus padres a través de las innumerables canciones que invocaban a una tierra de campesinos que cultivaban pequeñas parcelas, que guarecían al ganado en establos de madera durante los crudos inviernos, donde las primeras hayas de la primavera invitaban a un paseo por el bosque a recoger anémonas silvestres, enseñarles una Historia que se remontaba a los vikingos o al poder de obispos y monarcas, hacerles entonar cada fiesta patria los versos de Hans Christian Andersen: «I Danmark er jeg födt, der har jeg hjemme, der har jeg Rod, derfra min Verden gaan ( «He nacido en Dinamarca, allí tengo mi hogar y mis raíces, desde allí mi mundo tiene sentido») era, según el maestro, una necesidad natural e imposible de omitir. Sin embargo, el hecho de que los niños no podían identificarsè con Dinamarca de la misma manera que lo habían hecho sus padres y maestros, lo llevaba a plantearse si el esfuerzo por transmitir todos aquellos valores, que los menores no estaban en condiciones de captar completamente, no constituía una empresa sin sentido:

«(...) tanto las canciones cuanto la Historia no tienen una verdadera base donde asentarse y entonces el amor a la patria carece de fundamento (...) (33).

Igual que en la leyenda de Valdemar el Grande, los niños padecían un desdoblamiento al tener otra patria, otro idioma y otra Historia, donde el "Oíd mortales el grito sagrado", San Martín y Sarmiento eran algunos de los protagonistas. Cómo compatibilizar lo que venía como un eco lejano desde Dinamarca con el sonido contundente de esta nueva realidad, fue un problema que obsesionó a muchos y que muy pocos pudieron responder con soluciones concretas. En último análisis, todos terminaban aceptando que los valores de la danidad debían ser mantenidos en la escuela, para algunos porque éstos eran simplemente superiores y para otros, como el maestro Baekhöj, porque constituían un tesoro espiritual que enrique-

(33) Ibidem, pág. 40.

R. I., 1996, n.o 206 
cía a los niños. Sin embargo, para él la escuela tenía otro rol: debía servir para allanar el camino a la argentinización de los menores dejando que Sofie asesinase a Tovelille y la prudencia se impusiera al amor. Lo que no tenía en cuenta Baekhöj era que los roles de las dos esposas de Valdemar el Grande estaban invertidos para ambas generaciones. Para la primera Tovelille era Dinamarca, en tanto que para la segunda la bien amada del rey era el país adoptado por sus padres: la Argentina. De manera que la lucha cobraba dimensiones muy diferentes en ambas generaciones.

En definitiva, la escuela estaba sirviendo para reforzar un hecho que indefectiblemente tendría lugar tarde o temprano: el surgimiento de un nuevo sistema de valores y de una nueva identidad que no era ni completamente danesa, ni absolutamente argentina. Esa identificación surgía de la combinación de unos valores simbólicos que la primera generación transmitía a las siguientes a través de la educación y de otros tangibles que los menores incorporaban a su imaginario a partir de la experiencia cotidiana. Las clases de castellano, de geografía, de formación cívica y de historia argentina a cargo de maestros nativos, no venían sino a reforzar una identificación que, más allá del origen nacional de sus mayores, se daba naturalmente en los niños. Lo más problemático y en lo que se ponía mayor esfuerzo era precisamente en crear en los menores una identificación con el sistema de valores que sustentaban el Danskheden, en lograr que los niños respetaran esa herencia y que de algún modo para ellos adquiriera sentido entonar los versos: "I Danmark er jeg födt, der har jeg hejmme, der har jeg Rod» ("He nacido en Dinamarca, allí tengo mi hogar y mis raíces»).

Tácitamente todos sabían que la resonancia de esta canción que, en alguna medida resumía el sentido de mantener una educación danesa en medio de la pampa argentina, era muy inferior en el espíritu de los niños que en el de sus mayores. Sin embargo, se mantuvieron con tenacidad los intentos de transformar a la escuela en el medio más importante de preservar la herencia cultural danesa y la identificación nacional con Dinamarca, utilizando como vehículo a los integrantes de unas generaciones que tal vez jamás verían el verde transparente de las primeras hayas primaverales ni el azul intenso del Kattegat bajo el radiante cielo de Skagen: 
"Los versos de canciones como "Dinamarca, el más bello de los campos, el más hermoso de los prados", "Jylland, en medio de dos mares", "no soy más que un simple campesino", y muchas otras que se refieren tan directamente a la tierra danesa, son incapaces de despertar un sentimiento... entre quienes no tengan su hogar en Dinamarca» (34).

En general, podríamos presuponer que estos esfuerzos por mantener el idioma y los valores culturales y religiosos de Dinamarca obedecían a motivos de carácter más bien pragmático. Enviar a los menores a la escuela argentina hubiera implicado acelerar un proceso de argentinización que transformaría a los hijos en extraños para sus padres. En tanto que las escuelas de la comunidad, aún cuando compartían parcialmente su currículum con las públicas, prevenían ese proceso de asimilación, no sólo porque ayudaban a que los jóvenes conocieran la cultura de sus padres sino, sobre todo, porque les enseñaba a respetar aquel conjunto de tradiciones tan caras a sus mayores. Evidentemente hubo algo de esto. Sin embargo, los argumentos a favor del mantenimiento de una educación dentro de los límites de la comunidad tuvieron un carácter más bien simbólico donde jugaban un importante rol expresiones tales como: «la recreación y el mantenimiento del espíritu nacional danés entre los jóvenes», "despertar el amor a la cultura de Dinamarca», "permitir que los niños puedan compartir la riqueza de su lengua materna», "que en su pensamiento, su boca y su corazón se sientan identificados con el idioma y desarrollen un sentimiento nacional danés» (35). Ahora bien, la escuela tenía otro cometido, el de educar a los niños en el idioma y los valores del país adonde habían nacido e iban a vivir:

«sin olvidar que los niños son argentinos, que deben respeto a su gobierno y sus instituciones y que deben cumplir con sus deberes de ciudadanos» (36).

(34) Ibidem, pág. 42

(35) Tandils' Tidende, 15 y 21 de marzo de 1889 y 3 de junio de 1912; Aarsskrift for Dansk Skole Forening i Argentina (1911), págs. 35-44.

(36) Pedro Delmar, [26], pág. 17.

R. I., 1996, n. ${ }^{\circ} 206$ 
«estos niños han nacido bajo el cielo argentino y serán ciudadanos de este país, no debemos olvidar entonces que deben aprender lo mejor y lo más pronto posible el español» (37).

En este sentido la escuela contribuía a la formación de los menores en el nuevo sistema de valores que, en última instancia, era dano-argentino. Ahora bien, la concurrencia a las tres instituciones educativas con que contaba la comunidad no era ni de lejos perfecta. Se requerían medios económicos para educar a los hijos en alguna de las escuelas, de modo que la asistencia estaba condicionada por el éxito o el fracaso de las actividades productivas de los padres. En años de mala consecha o de bajos precios del cereal, la concurrencia disminuía notablemente. Otro factor que obstaculizaba la asistencia a las escuelas era la distancia. La mayor parte de los daneses vivían en zonas rurales, con lo cual los padres debían costear el pupilaje o el alojamiento durante el año escolar, lo que implicaba un costo aún mayor. De manera que las escuelas eran frecuentadas por alrededor de un 40 por 100 de los niños de la comunidad que se hallaban en edad escolar (38). Eran recurrentes las quejas de los maestros respecto a la baja asistencia, a la deserción y sobre todo al desnivel tanto etáreo como de conocimientos entre los niños de un mismo grado, ya que algunos comenzaban muy tardíamente la escuela y no tenían prácticamente ninguna destreza en el manejo del castellano, las matemáticas o el danés escrito. Sin embargo, estas situaciones tan alejadas de lo deseable no significaban que para los inmigrantes la educación fuese una cuestión menor. Por el contrario, la mayoría mostraba interés por brindar a sus hijos una preparación, tan siquiera

(37) Baekhöj LARs, [10], pág. 169.

(38) Este cálculo fue realizado utilizando los datos sobre la cantidad de alumnos que asistían a las escuelas de Tandil y Cascallares en el partido de Tres Arroyos, entre 1908 y 1929 en la primera y entre 1926 y 1930 en la segunda. Estos fueron confrontados con los registros bautismales de las iglesias de ambos asentamientos, donde estimamos la cantidad de niños que se encontraban en edad escolar. Tomamos en cuenta sólo a los menores que habían sido bautizados entre 8 y 12 años atrás al inicio de cada ciclo lectivo. Este cálculo sobreestima el número de potenciales alumnos, pues no tiene en cuenta factores como la mortalidad y la movilidad de los sujetos, por .ejemplo, el retorno de las familias a Dinamarca. 
rudimentaria y un fuerte respeto por la instrucción elemental, a la que la mayoría de ellos había accedido en Dinamarca donde la educación primaria era obligatoria desde 1814 (39).

En general, quienes no podían enviar a sus hijos a la escuela, contrataban maestros particulares. El huslaer (maestro a domicilio) se transformó en una "institución" alternativa que gozaban de gran difusión (40). Normalmente los maestros particulares se desempeñaban como peones o sirvientas de las explotaciones rurales y después de terminadas sus tareas instruían a los hijos del patrón. En algunas ocasiones varios productores contrataban a un maestro que utilizaba una de las chacras para reunir a sus alumnos residentes en los alrededores en una especie de escuela rural ad hoc. Esta forma de instrucción asistemática y por demás inconstante, cubrió parte de las falencias educativas de quienes por razones económicas o de distancia no tenían chances de asistir a las escuelas de la comunidad. El problema más grave de esta clase de educación era el aislamiento que generaba respecto de los valores de la nueva sociedad. En un medio rural con maestros, padres y hermanos que se comunicaban solamente en danés, los menores quedaban rezagados en el camino de la integración a este nuevo sistema de valores dano-argentinos. Este tema no fue ajeno a las discusiones en el interior de las congregaciones y sus escuelas, sobre todo por el problema de que los alumnos del huslaer obtenían una instrucción culturalmente sesgada ya que sólo aprendían en danés y sobre Dinamarca.

Del otro lado del espectro, las escuelas de la comunidad mostraban preocupación por aquellos menores que ni siquiera habían podido tener un maestro particular y se habían visto obligados, por motivos diversos, a acudir a la escuela pública. Así, la congregación de Tandil ideó un colegio de verano. Durante el corto tiempo que los jóvenes, provenientes de lugares tan distantes como Buenos Aires o Rosario, tomaban estos cursos estivales, trataban de captar el «espíritu danés» incorporando a grandes rasgos: la Historia de Dinamarca, los salmos

(39) En 1814 la gran reforma educativa danessa introdujo la instrucción obligatoria de los menores entre siete y catorce años.

(40) Pedro Delmar, "Lidt den danske Huslaerinstitution under argentinske Flag", en Aaarsskrift for Dansk Skoleforening i Argentina (1928), págs. 19-23. 
matinales, la biografía de Grundtvig, los cuentos de H. C. Andersen y algún que otro rudimentario conocimiento de Física y Matemáticas, coctel de saber que indefectiblemente era llevado adelante en danés (41).

A ambos extremos de una escuela que intentaba perpetuar el sistema de valores daneses sin dejar de reconocer la necesidad de allanar el camino a la identificación de los menores con la nueva sociedad, se hallaban aquellos que recibían una educación eminentemente asistemática y sesgada hacia Dinamarca y los que concurriendo a la escuela pública, a la carrera, trataban de rescatar el espíritu de la tierra de sus mayores durante los calurosos veranos tandilenses. En último análisis, todos eran dano-argentinos, sin embargo, sólo quienes concurrían a la escuela incorporaban las dosis justas que contribuirían a internalizar ambos sistemas sin que uno fagocitara al otro.

Aunque las congregaciones se interesaban por el constante aislamiento en que eran educados los menores que contaban tan sólo con un maestro a domicilio, su máxima preocupación eran aquellos que concurrían a la escuela pública, donde Tovelille se encontraba mucho más expuesta al acecho de Sofie. Desafortunadamente, no sabemos qué proporción de los menores de la comunidad se hallaban en esta situación. Sin embargo, a juzgar por la baja concurrencia a la escuela de verano (42), pero, sobre todo, por el grado de difusión de los maestros particulares en las chacras, pensamos que no eran demasiados (43). Los esfuerzos de la iglesia por mantener el idioma y

(41) Secoión de información general en Aarsskrift for Dansk Skoleforening $i$ Argentina (1927).

(42) La asistencia a la escuela de verano no superaba, generalmente, los quince alumnos anuales. La mayor parte de ellos provenían de lugares donde no había escuelas danesas y donde el grupo étnico era de muy reducidas dimensiones. No sabemos si la baja concurrencia se debía al escaso interés de los padres que enviaban a sus hijos a las escuelas públicas, en que estos recibieran instrucción complementaria en danés, o que, más bien, tenía que ver con que pocos niños de colectividad concurrían a las escuelas del Estado, ya que sus necesidades eductivas estaban cubiertas por el sistema de maestros particulares o asistiendo a los establecimientos educativos de Tandil, Cascallares en el partido de Tres Arroyos y Lumb en el de Necochea. Nuestra hipótesis es que ocurría esto último.

(43) Pedro Delmar, [40], pág. 21; Entrevista con Karen Sunesen, Tres Arroyos, noviembre de 1988; Entrevista con Ricardo Albeck, Necochea, diciembre de 1988; Entrevista con Alice Larsen Rabal, Tandil, abril, 1993. 
preservar la cultura danesa entre las generaciones que deberían asumir los destinos de la matriz de instituciones que había sido creada por los inmigrantes no eran en vano, estaban encontrando respuestas favorables en la comunidad.

\section{CONSIDERACIONES FINALES}

A pesar de la inexistencia del cisma eclesial o de la afiliación declarada a una u otra ala de la iglesia danesa, el despertar nacionalista posterior a la derrota de 1864 frente a Prusia y la difusión de los principios grundtvigianos traídos por algunos de los inmigrantes que llegaron a la Argentina en los últimos años del siglo pasado, se hallaban por detrás de los intentos de preservar un sentimiento de identificación nacional con Dinamarca llevado adelante por las instituciones más importantes de la comunidad: la iglesia y la escuela. Desde esos ámbitos y apoyados por la difusión de sus actividades en las publicaciones comunitarias (44), se recreaba la etnicidad del grupo basada en la trasmisión, por medio de la educación, de un conjunto de símbolos socialmente determinados. Los inmigrantes habían sido educados en un sistema de valores que determinaba su pertenencia a la cultura de Dinamarca. Parte de ese sistema era impuesto a los menores nacidos en la Argentina con el fin de condicionar la dirección de su identificación étnica y de crear un sentimiento de pertenencia nacional que los hiciera partícipes a distancia de lo que Benedict Anderson ha llamado "comunidad imaginada", al adoptar los emblemas y las metáforas culturales que definían la nacionalidad danesa. Sin embargo, las nuevas generaciones se hallaban expuestas a otros símbolos y otros valores que orientarían su pertenencia en un sentido diferente. Los menores habían nacido en otra sociedad cuya nacionalidad se definía con símbolos, emblemas y metáforas culturales diferentes a las que eran empleadas para orientar su identificación con la patria de sus ancestros. Esta nueva realidad era una presencia permanente

(44) Especialmente en los periódicos Tandils' Tidende y Syd og Nord y en los Anuarios publicados por las escuelas de Tandil y Cascallares en el partido de Tres Arroyos.

R. I., 1996, n. ${ }^{\circ} 206$ 
en la vida de los menores, una fuerza que los empujaba a definir su pertenencia a otra "comunidad imaginada»: la nación argentina, a la que la élite dirigente se había empeñado en consolidar mediante una práctica y un discurso «nacionalizador» que tuvo su principal escenario en las escuelas primarias del Estado y su punto culminante en torno al centenario de la revolución de Mayo (45).

Los maestros y los pastores eran conscientes de esta doble identificación y trabajando en pos de reforzar lo más débil, aquel sistema simbólico que tenía sus raíces a quince mil kilómetros de distancia, fueron dando origen en los niños de la comunidad a una nueva identidad que no comulgaba plenamente con ninguna de los sentimientos patrios que estaban en juego, sino que más bien tomaba elementos de ambos y se constituía en una especie de híbrido dano-argentino que marcaba un paso adelante en el camino de la asimilación del grupo a la nueva sociedad.

Ahora bien, el carácter de ambos componentes de esta identidad era diverso, pues la identificación con los valores daneses por parte de las generaciones nacidas en la Argetina, difería no sólo en grado sino fundamentalmente en naturaleza con la de sus mayores. Para los inmigrantes la identidad nacional recreada en la nueva sociedad a través de un marco de instituciones comunitarias, proveía un sucedáneo dentro del cual podían revivir parcialmente su común experiencia pasada. Sólo ellos, que habían experimentado personalmente la herencia del Viejo Mundo, tenían un genuino y tangible sentido de pertenencia a aquel sistema de valores nacionales. Estas experiencias concretas y personales permanecían, sin embargo, inaccesibles a los miembros de las generaciones nacidas en la Argentina. La herencia ancestral era un pasado intangible transformado en un conjunto de ideales que sus mayores les trasmitan en el intento de forjar su identidad étnica, evitando que la cultura de la

(45) Lilia Ana BeRTONI, "Construir la nacionalidad: héroes, estatuas y fiestas patrias, 1887-1891", en Boletín del Instituto de Historia Argentina Americana Dr. Emilio Ravignani, n.o 5 (1992), págs. 77-111; Ibidem, "Nacionalidad o cosmopolitismo. Las escuelas primarias y un debate sobre el futuro de la Argentina de fin de siglo" ponencia presentada en las IV Jornadas sobre Colectividades, Cemla-Museo de Roca-Ides-UNLU, Buenos Aires (28-30 de octubre 1993). 
nueva sociedad los fagocitara y que más allá de la vida de los propios inmigrantes quedasen tan sólo, Larsens, Jensens o Petersens hispanoparlantes, casados con nativas, padres de vástagos trigueños incapaces de relacionar «El patito feo» con la campiña danesa y con el compositor de «I Danmark er jeg Födt, der har jeg hejemme, der har jeg Rod...».

Los brios preservacionistas de la iglesia y la escuela lograron que esa "ideología» (46), que transcendía los elementos tangibles de la identificación nacional tradicional, ocupase su lugar en el imaginario de, por lo menos, la segunda generación. Ese conjunto de valores intangibles fue el reaseguro de la danidad ante el otro sistema, el que los miembros de la comunidad experimentaban diariamente y que de no haberle puesto freno se hubiera llevado a la segunda generación a través de la escuela pública y de la interacción con lo que era su natural sistema simbólico: el de la cultura y los valores argentinos.

Mientras que en el seno de la propia comunidad padres e hijos experimentaban su identificación con lo nacional en dos niveles diferentes, donde si bien todos sabían que los roles de Tovelille y Sofie estaban cambiados nadie se atrevía a explicitarlo en un discurso claro, en el ámbito más amplio de las relaciones del grupo con la nueva sociedad, que la clase dirigente trataba de homogeneizar, se empleaban las mismas palabras para referirse a dos realidades distintas, cumpliéndose plenamente el acerto "hay otros mundos, pero están escondidos en éste». De un lado, los miembros de la élite gobernante se habían propuesto, desde la década de 1880, articular una acción sostenida y eficaz orientada a construir la nacionalidad argentina y a consolidar las bases de la joven nación. A tal fin crearon un aparato institucional en el que la escuela primaria pública tenía un rol primordial. Las tradiciones, la revalorización del pasado y el respeto a los prohombres sin cuya contribución primordial la patria no hubiese sido posible, eran sentimientos cuyos principales canales de transmisión debían encontrarse en la escuela y en el uso del castellano como lengua oficial de la enseñanza.

(46) J. Fishman y V. NAHIRNY, "American Inmigrant Groups: Ethnic Identification and the Problem of Generations", en Sociological Review 13 (1965); Ibidem, "Ukranian Language Maintenance efforts in the United States", editado por Joshua Fishman, Mounton (1966).

R. I., 1996, n.o 206 
Del otro lado, desde un espacio escondido en el sudeste bonarense (47), la élite de la comunidad danesa utilizaba iguales argumentos en favor de la reconstrucción de otra nacionalidad. Haciendo propias las ideas de los grundtvigianos, estos inmigrantes descargaron todo su arsenal nacional en unas escuelas primarias que, sin lograr sustraerse al apartado de control que el gobierno argentino utilizaba para afianzar la argentinidad en los ámbitos de la enseñanza privada (48), reivindicaban a los próceres, a las tradiciones y al pasado de otra patria en otro idioma, pero haciendo uso de un discurso y de unos mecanismos virtualmente idénticos a los empleados por la élite gobernante.

This study examines certain aspects of the process of adaptation to a new society faced by a north European ethnic group: Danish settlers in rural districts of the central-southern province of Buenos Aires. The author attempts to analizae the influence among Danes in Argentina of a religious movement, widely extended in Denmark in the last three decades of the nineteenth century, which aimed to revive Danish nationalism after the defeat during the war against Pussia in 1864. The Danish Lutheran Evangelical Church in Argentina tried to maintain the religious and national identity of these inmigrats, and encouraged community schools to create a double national identity, by the preservation and propagation of the social and cultural values of Danish national iconography among successive generations born in Argentina.

(47) Esta situación se reiteraba en otras experiencias de escuelas comunitarias en distintos ámbitos del país. Por citar sólo algunos ejemplos mencionaremos, además de la escuela italiana que constituyeron el acicate para la organización de una enseñanza primaria que tenía como eje la nacionalidad argentina, a las escuelas de las colonias de Santa $\mathrm{Fe}$, alemanas, judías, suizas, etc.; a las de la comunidad galesa de Chubut, a las ruso-alemanas de las provincias de Buenos Aires y La Pampa.

(48) Respecto de los mecanismos de control empleados por la élite gobernante en las escuela privadas de las distintas comunidades de inmigrantes, ver Lilia Ana BERTONI, [45]. 